\title{
An exotic career
}

\author{
Jörg Mayer, MS, DVM, DABVP (ECM), Dip. ECZM (Small mammal), \\ Associate Professor of Zoological Medicine, Department of Small \\ Animal Medicine and Surgery, University of Georgia, College of \\ Veterinary Medicine, Athens, GA.
}

\begin{abstract}
Dr. Mayer talks about his experiences treating exotic animals abroad and encourages veterinary students to pursue this exciting area of veterinary medicine.
\end{abstract}

You hold a master's degree in wild animal health (Royal Veterinary College, London) and serve as a Diplomate of the American Board of Veterinary Practitioners as a specialist in Exotic Companion Mammals in addition to being a Diplomate of the European College of Zoological Medicine. You also currently serve as the President of the Association of Exotic Mammal Veterinarians. How did you become interested in exotic animals?

When I was at veterinary school in Budapest, Hungary, we were not taught much about the phenomenal anatomy, physiology and pathology of exotic animals. I was always interested in any area of study that has been less researched, and I soon realized that the world of non-traditional pets and exotic animals exactly suited my interests. My interest in learning more about exotic animals also stemmed from the fascinating ways in which they differ from domesticated animals. I was lucky that one of the clinicians from the exotic pet clinic at the university was an extremely good teacher and took a sincere interest in my desire to learn more about exotic pet medicine. I spent most of my elective time in one-on-one lessons with him in the exotic animal clinic, which really cemented my love for this exciting field.

While working on your doctorate degree from the Veterinary University of Budapest, Hungary, you spent 6 months working with veterinarians in South Africa and Namibia. Tell us more about this experience.
I knew that I would not have another chance to spend a significant time traveling abroad after graduation, so I decided to combine my love for exotic destinations with an opportunity to work outside the 'normal' setting. I traveled to Namibia to see the country as a tourist, and then I did an externship with a large animal practitioner. Then I went on to South Africa and did an externship in the exotic clinic at the Veterinary University in Pretoria. These experiences showed me that there is a need for specialists in non-traditional pets all over the world. A friend of mine from veterinary school was conducting his $\mathrm{PhD}$ research at the Krueger National Park at the same time, so I was able to join him for a field trip and stay at the research camp in the park. The experience confirmed my belief that the field of exotic animal medicine can offer a variety of job opportunities if you are really dedicated to it, and I realized that my dream was a legitimate thing to pursue.

\section{You also studied wild tree kangaroos in Papua New Guinea as part of an internship at Roger Williams Park} Zoo in Providence, RI. What have you learned from your research experience in the field?

This trip came right after my internship in zoological medicine, and it was a great opportunity to learn about another aspect of working with exotic animal species. I still think of that time often, since it was truly one of my best and most intense experiences. It was also a reality check, however. I was a bit naive and imagined that fieldwork would just involve looking at some exotic animals from a distance, noting their behavior and analyzing the data later on the video screen, but it was

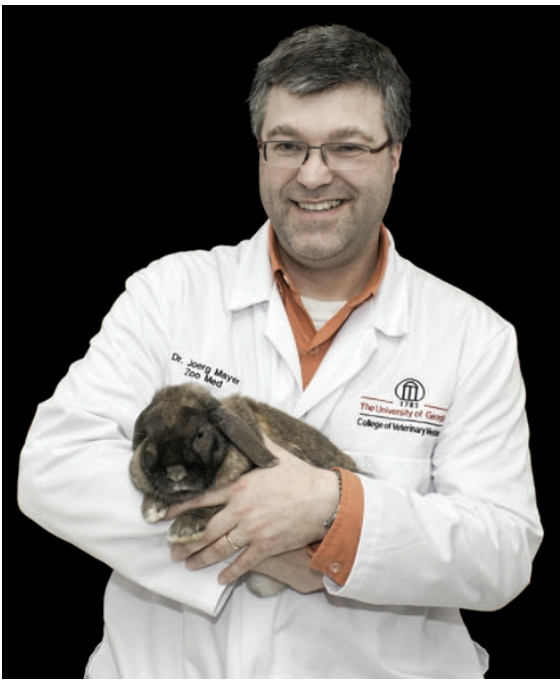

very different from that. Since our research was in the cloud forest, we were constantly wet and cold. At one time I personally had about 80 flea bites counted on one leg! Eating rice and vines on a regular basis, not having access to any regular toilet or shower facility and walking every day for hours up and down mud-covered hills really cleared up my romantic idea of field research. While I enjoyed the experience with all its facets, I came to the conclusion that a field research job would not be my cup of tea and that I would need a job in a more traditional setting. I guess I found my limits!

You have held academic positions at Tufts University and the University of Georgia, Athens. What is the most important thing that you try to teach your students?

Many students think that medical care for exotic animals is different, when in reality it is the same medicine as applied to dogs and cats or even to humans. It is a great pleasure for me to see students who are initially puzzled or even intimidated by exotic species suddenly become confident in their actions and realize that, if they approach the management of a case with the common sense that they have developed during the first three years of veterinary school, they can logically work up more or less every case. 